\title{
Spatial Heterogeneity of Artificial Reefs Functioning according to Wind-Induced Lagrangian Circulation
}

\author{
Marie-Aude Pradal ${ }^{1}$ and Bertrand Millet $^{2}$ \\ ${ }^{1}$ Earth and Planetary Sciences, Johns Hopkins University, Baltimore, MD 21218, USA \\ ${ }^{2}$ Mediterranean Institute of Oceanography, UMR 7294 CNRS and Aix-Marseille University, Campus of Luminy, 13288 Marseille, France
}

Correspondence should be addressed to Bertrand Millet; bertrand.millet@univ-amu.fr

Received 15 November 2012; Accepted 1 January 2013

Academic Editors: A. Bracco and S. Focardi

Copyright (C) 2013 M.-A. Pradal and B. Millet. This is an open access article distributed under the Creative Commons Attribution License, which permits unrestricted use, distribution, and reproduction in any medium, provided the original work is properly cited.

In the scope of the program "Récifs Prado" for artificial reef immersion in the bay of Marseilles (southern France), we adapted the fine resolution $(100 \mathrm{~m})$ of the 3D numerical model POM (Princeton Ocean Model) to compute the typical patterns of the wind induced circulation within the bay. In addition, we derived from those results the Lagrangian trajectories of planktonic particles drifting over periods of 3 days, both from natural habitats to colonize the reefs, and inversely from the reefs to enrich peripheral ecosystems. Results emphasized the high spatial heterogeneity of the reefs functioning at short scales. First, reefs were submitted to a general southward particle flux, being colonized from the northern bay and then impacting the southern bay $50 \%$ and $40 \%$ of the time, respectively. Second, adjacent reefs frequently showed contrasted impacts, with fluxes simultaneously oriented offshore or inshore, in opposite directions. Third, at the top of reefs particles were released both southward and northward $32 \%$ and $8.6 \%$ of the time, respectively; when at the bottom of reefs particles were only released southward $40 \%$ of the time.

\section{Introduction}

The ecosystem in the bay of Marseilles, located at the eastern part of the gulf of Lions in the northwestern Mediterranean, is impacted by the activities of the second largest commercial port in France and an urban community of about 800,000 inhabitants (Figure 1). In 2001, the city of Marseilles was promoted in program aimed at increasing the biodiversity of the ecosystems in the bay and promoting the local fisheries. To achieve this, an ambitious project consisting of the immersion of artificial reefs of production, the largest in France, was started in 2007. A total of $35,000 \mathrm{~m}^{3}$ of diversified artificial structures were deployed, with structures of 6 different kinds of shapes and materials: rock piles, cubic concrete blocks, stake beds, steel baskets, chicanes, and high cable networks. The immersion zone of 220 ha was chosen in the central part of the bay, close to the cape of Endoume, between depths of $20 \mathrm{~m}$ and $30 \mathrm{~m}$. The structures were arranged as 6 adjacent triangular villages $(300 \mathrm{~m})$ separated by narrow channels (Figure 2). This project benefited from available knowledge of local benthic communities, natural ichthyofauna and water circulation experiments in the bay. Moreover, two factors influenced the choice of the immersion zone, between cape of Endoume and Frioul archipelago: the proximity to the wide Posidonia oceanica seagrass meadow of Prado and the presence of the natural rocky shores of Pomègues island and cape of Endoume. Thus, the geographical proximity of the artificial reefs to potential zones acting as sources of biological particles such as eggs and larvae was considered as a beneficial factor for rapid colonization.

It is well known in marine environments that the motions of planktonic organisms are essentially controlled by current direction and intensity. In addition, the success of the reefs colonization and impact for natural habitats strongly depend on their efficient position and orientation to natural ecosystems $[1,2]$. Therefore, it was important not only to consider the geographical distances between artificial reefs and natural peripheral habitats, but to take more accurately into account the hydrodynamic connections locally induced by the predominant winds within the bay of Marseilles, as the dynamics connect planktonic organisms drifting from the source zones to the reefs, and inversely from the reefs 


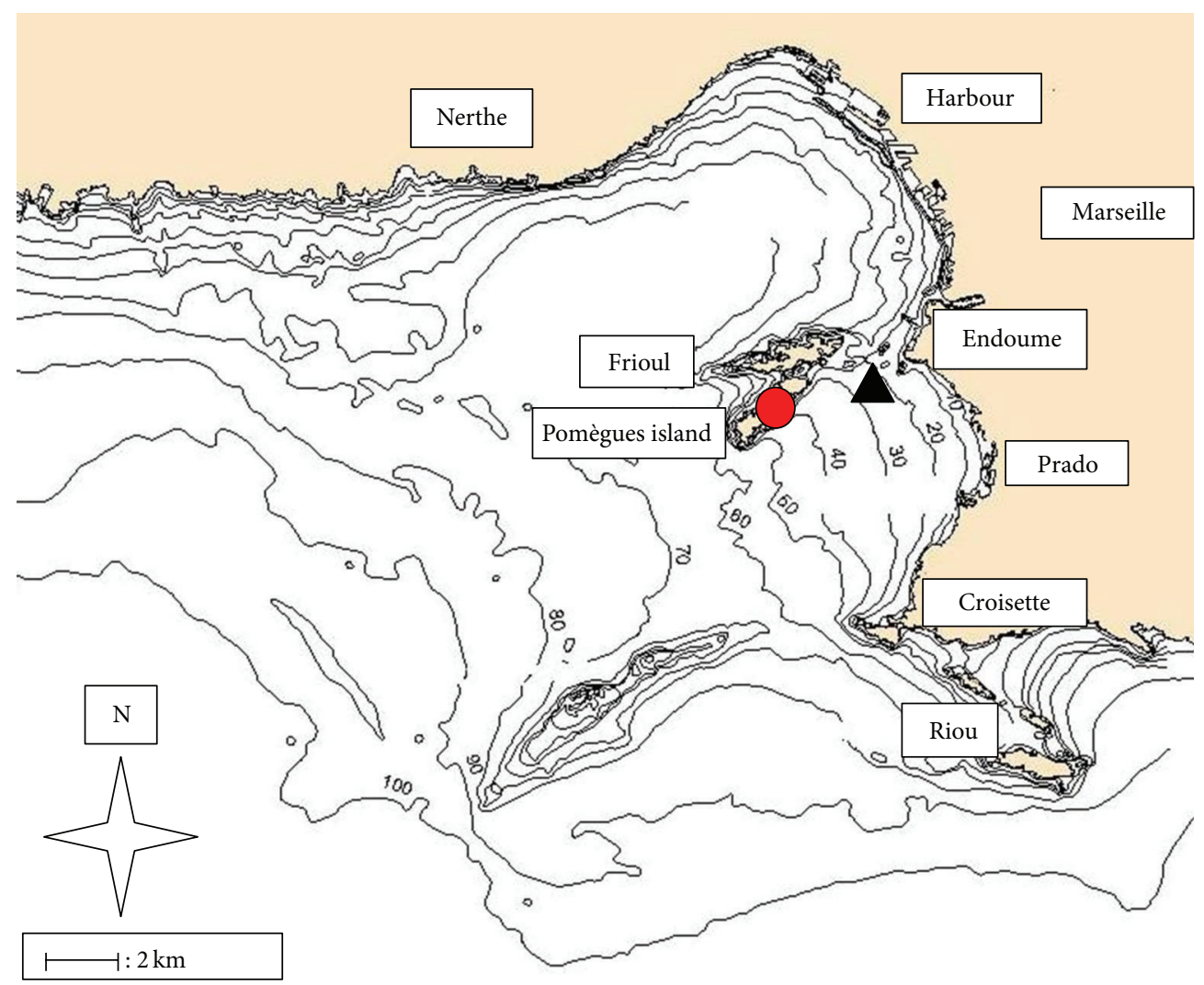

- Artificial reefs immersion zone

Meteorological station of Pomègues island

FIGURE 1: General map of the bay of Marseille with bathymetry $(\mathrm{m})$, artificial reefs immersion zone, and meteorological station of Pomègues island.

to the rest of the bay. Thus, the Mediterranean Institute of Oceanography initiated in 2002, in the scope of a $\mathrm{PhD}$ project [3], a research program to implement a fine resolution $3 \mathrm{D}$ model of the typical circulation induced by the wind within the bay of Marseilles. The first results of this study were published in a previous paper [4], which presented the calibration and validation (i) of the Princeton Ocean Model (POM) adapted to the bay of Marseilles. The wind-induced current fields (ii) at both the surface and the bottom of the water column as well as a first set of trajectories (iii) of planktonic particles at the vicinity of the reefs were presented in this first article.

The present paper shows a new set of synthetic results of this modeling task undertaken in the bay of Marseilles [4]. These results present the Lagrangian trajectories of particles describing the connection between artificial reefs and peripheral habitats. These habitats are considered as potential source or sink of particles released on the reefs. Results are interpreted and discussed here in order to provide decision makers and biologists with a typology of hydrodynamic connections, potentially providing some insight on field observations collected during the monitoring of the reef colonization.

\section{Methods}

2.1. Local Wind Regime. The local wind regime was obtained from a 30-year (1976-1998) time series recorded at the MetéoFrance meteorological station located $3 \mathrm{~km}$ from the reefs at highest point of Pomègues island, which is the southern part of Frioul archipelago (Figure 1). The wind rose considered in our computations and presented in Figure 3, shows the four prevailing wind directions for wind events greater or equal to $2 \mathrm{~m} \cdot \mathrm{s}^{-1}$ : NW $340^{\circ}$ and $320^{\circ}$, SE $120^{\circ}$ and $160^{\circ}$. The frequencies of occurrence in time over the whole period for those 4 wind directions are: $17.7 \%$ and $14.1 \%, 8.6 \%$ and $6.8 \%$, respectively. Although the intermediate sector SE $140^{\circ}$ is almost absent at Pomègues station (only $2.2 \%$ in time) due to the orographic masking effect of the southern hills located near cape Croisette (Figure 1) [4], its frequency was added when both dominant SE sectors $120^{\circ}$ and $160^{\circ}$ needed to be simultaneously cumulated. The four wind sectors taken into account in this study can be considered as significantly representative of the local wind regime, because Figure 3 confirms that no adjacent sector remains efficient in this Mediterranean area, and all wind intensities considered 


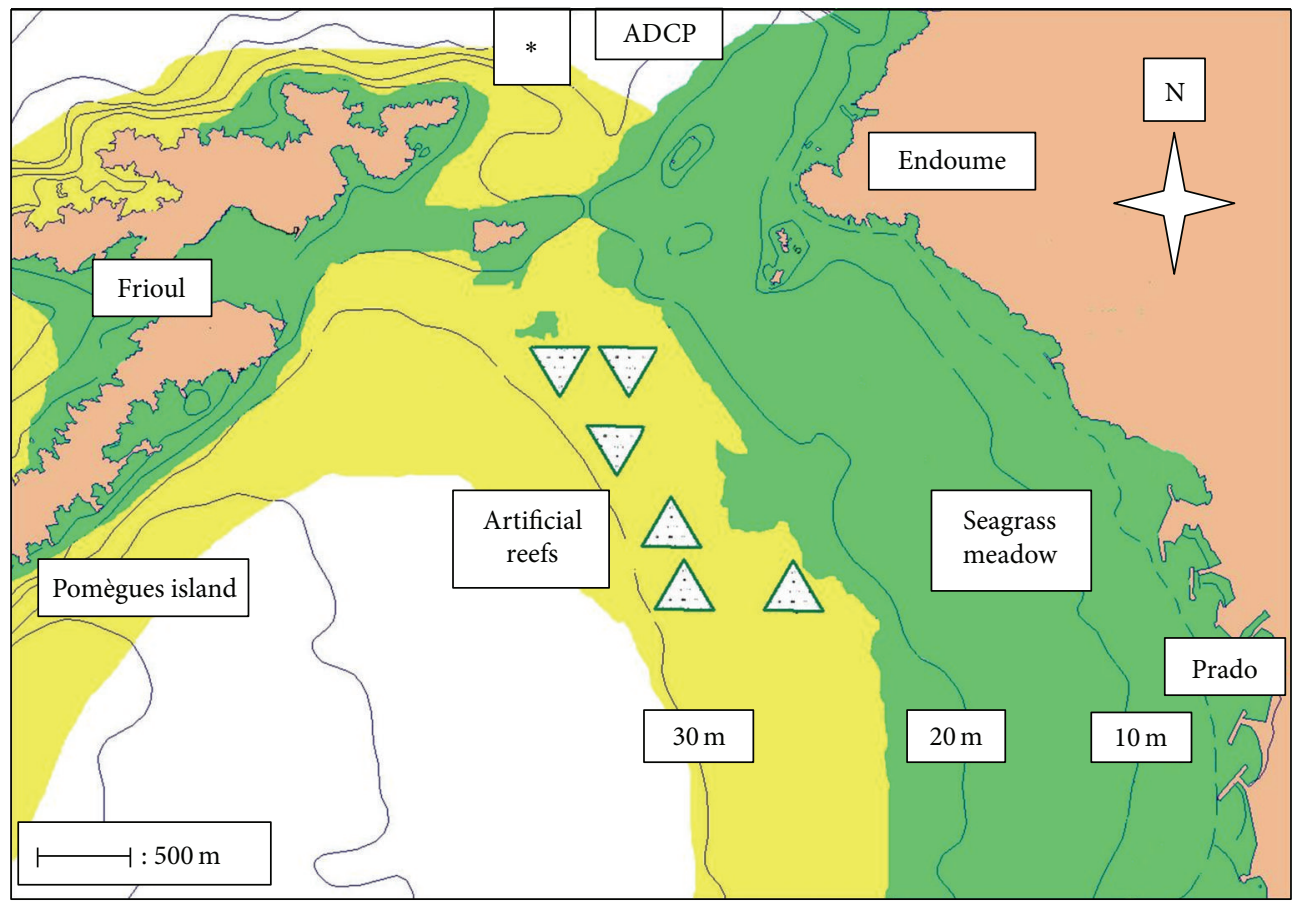

FIGURE 2: Reefs zone design in the bay of Marseilles with locations of the ADCP station (*) and the 6 triangular villages (to scale), in which artificial structures are dispatched.

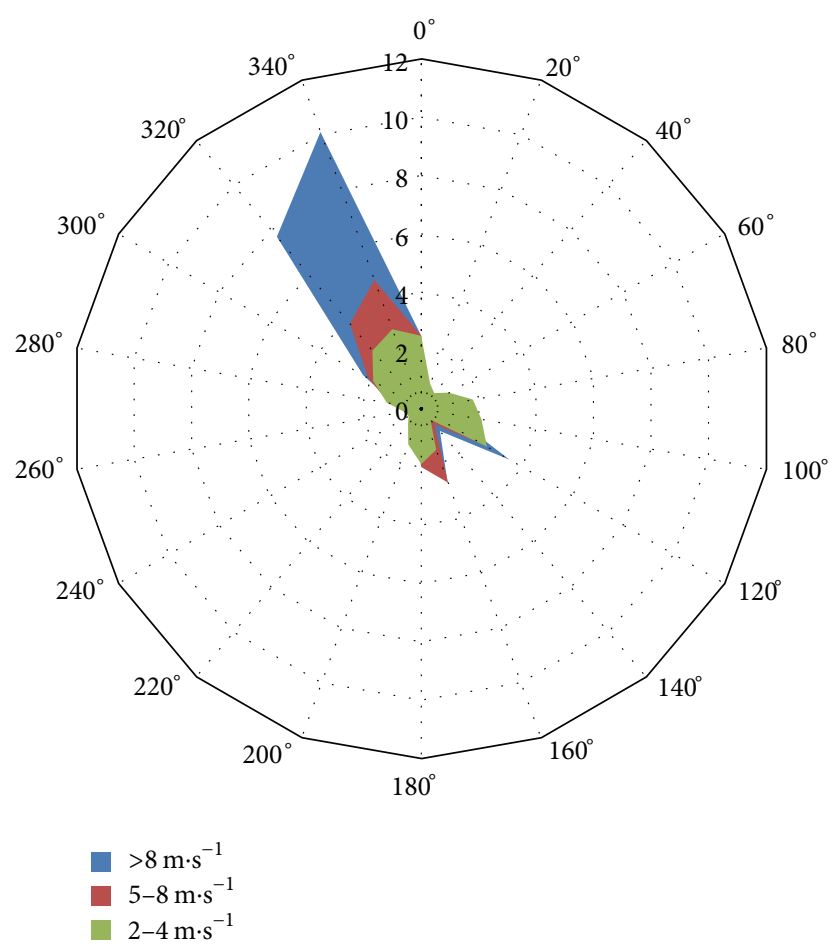

Figure 3: Wind measurements at the Metéo-France station of Pomègues island, over the 1976-1998 period; colors mean the three classes of wind intensities: $2-4,5-8$, and $>8 \mathrm{~m} \cdot \mathrm{s}^{-1}$. $\left(>2 \mathrm{~m} \cdot \mathrm{s}^{-1}\right)$ are liable to promote hydrodynamic motions within the bay.

2.2. Source Zones of Particles. We identified, from discussions with biologists and as a result of long-term investigations in situ, 5 zones located around the bay of Marseilles corresponding to different kinds of habitats and supposedly acting as sources of planktonic particles (e.g., eggs and larvae) capable of colonizing the artificial reefs. Figure 4 presents the locations of these 5 zones. These correspond to the (i) natural rocky habitats along the northern Nerthe coast and the eastern Frioul and southern Riou archipelagos, (ii) the man-made pier of the commercial Harbour, and (iii) the western Prado seagrass meadow. We systematically computed all particle trajectories drifting from each horizontal grid mesh $(100 \mathrm{~m})$ within each zone considered and for every vertical sigma level, over periods of 3 days, and successively forced by the 4 prevailing wind conditions.

2.3. Numerical Model. We used the 3D numerical model POM developed at Princeton University [5]. POM is based on a set of primitive equations and uses a free surface, sigma coordinates, a semi-implicit finite differences numerical scheme on a Arakawa C grid, and a 1-order turbulent closure scheme to compute vertical diffusion coefficients. In addition, a specific code was written in our study to compute the Lagrangian trajectories of passive planktonic particles drifting in the $3 \mathrm{D}$ current fields previously computed by POM. 


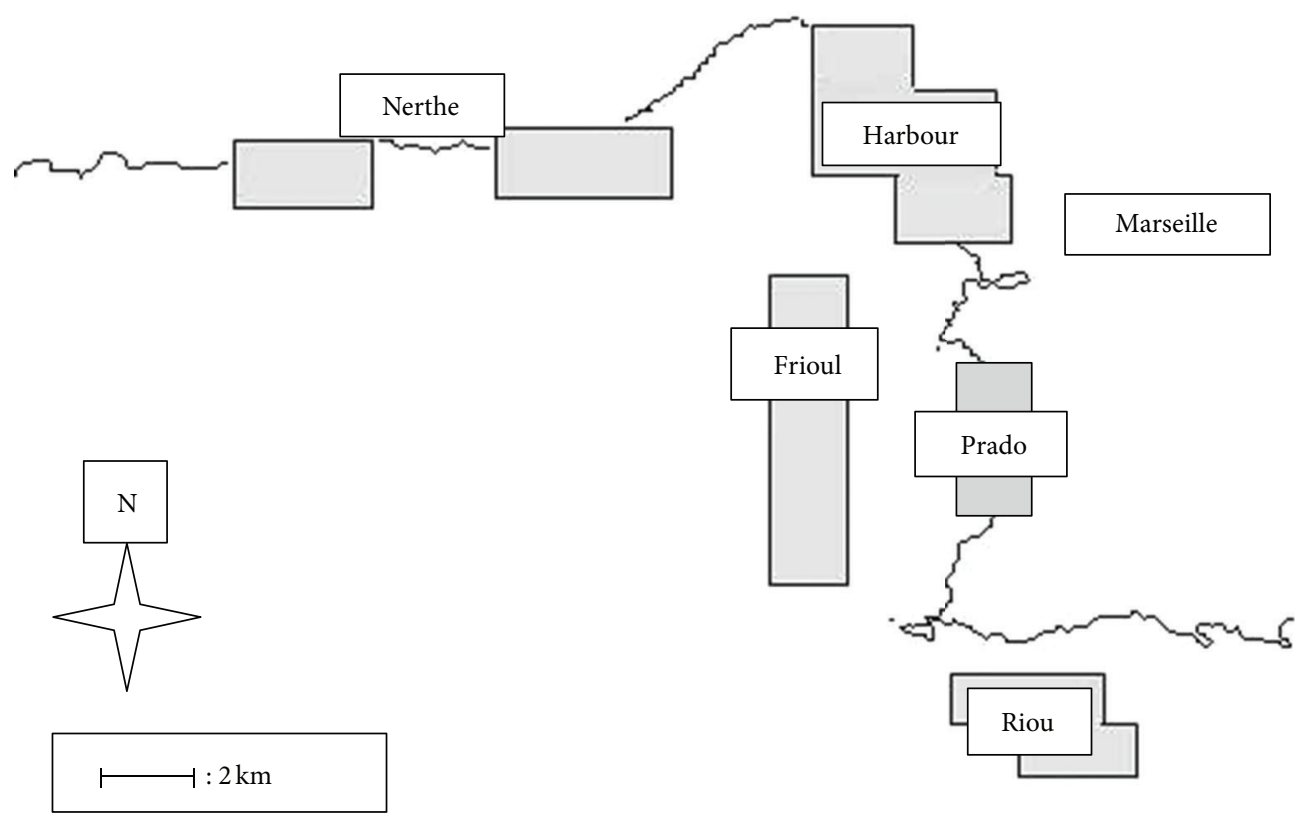

FIGURE 4: Location of the 5 coastal zones identified in the bay of Marseilles to act as sources of particles for the artificial reefs colonization.

A digital map of the bathymetry was compiled from the data extracted of the 1/50000 map of the Hydrographic and Oceanographic Department of the French Navy (SHOM) [6]. The domain considered in this study covered an area of $25 \times 35 \mathrm{~km}$ with a fine horizontal resolution of $100 \mathrm{~m}$ and 11 vertical sigma levels [4]. The only forcing applied to the water mass in our model was a homogeneous and stationary wind, as it was supposed to be the prevailing and constant forcing function of water circulation within the inner part of the bay, east of Frioul archipelago, around the reefs zone. Actually, this area is weakly impacted by the offshore general circulation of the northwestern Mediterranean. We therefore considered free radiative conditions for all open boundaries of the domain as presented in previous publications $[3,4]$. These hypotheses were later reinforced by the good agreement between our results and those of a recent study modeling the circulation with the code MARS 3D, at a much larger scale in the bay (lower resolution of $200 \mathrm{~m}$ ), and considering both forcings of winds and offshore circulation, computed from large scale atmospheric and NW-Mediterranean circulation models, respectively [7].

Details of the calibration and the validation of both the $3 \mathrm{D}$ model and the computation of trajectories are provided in previous publications $[3,4]$. For example, a 3-month time series of current measurements (from October to December 2003) has been recorded ( $10 \mathrm{mn}$ frequency) at a ADCP (Acoustic Doppler Current Profiler) station, immerged off the cape of Endoume at $40 \mathrm{~m}$ depth and close to the reefs zone (Figure 2). Figure 5 presents the comparison between vertical profiles of current direction, computed by the model and measured at the ADCP station: M1, M2, and M3 and S1, S2, and S3 profiles corresponded to current directions measured during NW and SE wind events, respectively. The relatively good adequation between computed and measured profiles of current direction confirmed the validation of the model in our study area.

\section{Results}

3.1. Wind-Induced Current Fields. Simulations of windinduced circulation with POM led to compute 44 current fields over the whole domain $(25 \times 35 \mathrm{~km})$ for the 4 wind directions and the 11 sigma levels considered. Each computation was run for 48 hours with homogeneous and stationary $10 \mathrm{~m} \cdot \mathrm{s}^{-1}$ wind forcing and with constant water temperature of $14^{\circ} \mathrm{C}$ as initial conditions. For example, and to give a better understanding of where the trajectories of particles involved into the reef functioning come from, Figure 6 presents the current fields computed at $20 \mathrm{~m}$ depth (the mean depth of the artificial reef structures). The results are presented for both dominant winds NW $340^{\circ}$ (Figure 6(a)) and SE $120^{\circ}$ (Figure 6(b)).

3.2. Wind Regime Analysis. To decide for how long the particles should drift in the model, it was necessary to determine the maximum duration of a scholastically significant steady wind event. We analyzed the whole time series of 2800 wind observations available at the Pomègues station. Figure 7 presents histograms of the relationships between a range of wind event durations and the number of wind events corresponding to each duration, with distinction between the cumulated W-NW-NE directions from W $260^{\circ}$ to $\mathrm{NE} 40^{\circ}$ (Figure 7(a)), and E-SE-SW directions from NE $50^{\circ}$ to SW $250^{\circ}$ (Figure $7(\mathrm{~b})$ ). Results showed that $90 \%$ of W-NW-NE wind events did not exceed the limit period of 3 days, and $90 \%$ of E-SE-SW wind events did not exceed 2 days. We concluded 

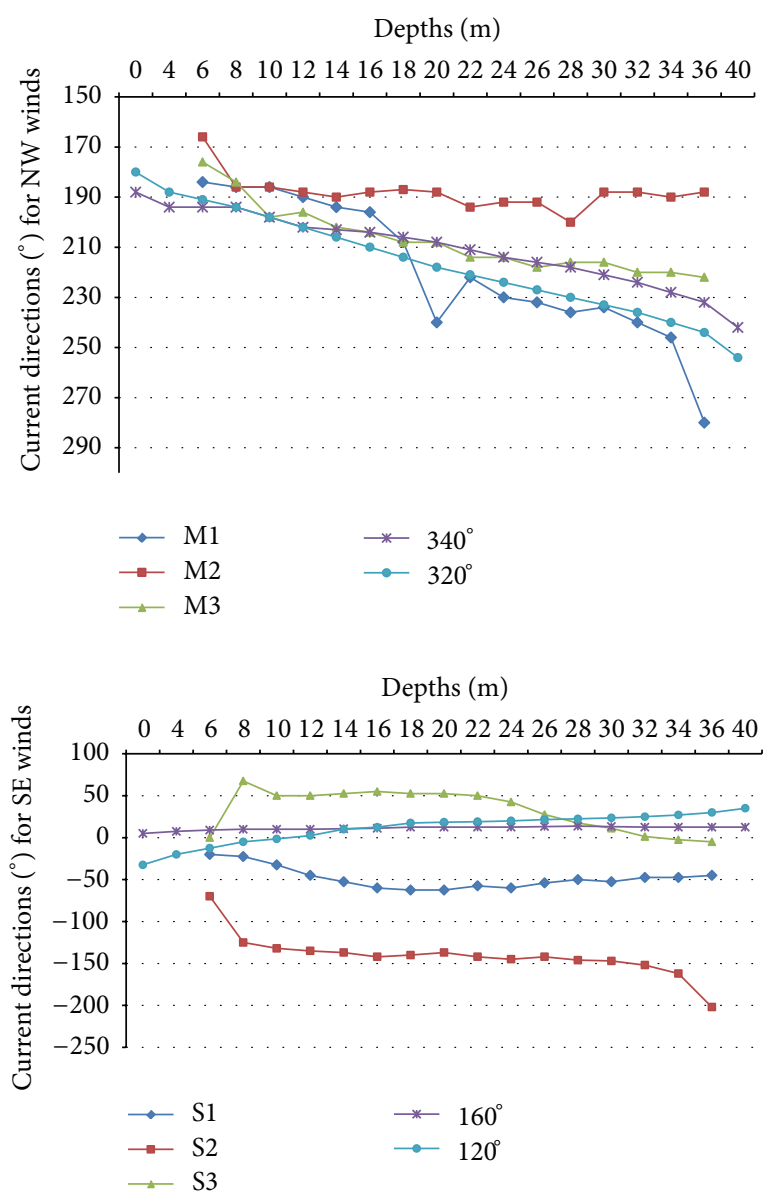

FIGURE 5: Model validation in current direction. Comparison between vertical current directions computed at the ADCP station under NW $320^{\circ}-340^{\circ}$ and SE $120^{\circ}-160^{\circ}$ winds, with measurements at the same station under NW (M1, M2, M3) and SE (S1, S2, S3) wind events.

that our studies of particle drifting could be representative of the environmental conditions of the bay with trajectories computed over the maximum period of 3 days.

3.3. Recruitment Areas for Artificial Reefs. The synthetic analysis of all the trajectories computed from the source zones presented in Figure 4 allowed the drawing of the stochastic map of all the source points in connection with the reef zone, within a period of 3 days. The frequencies attached to each source point are the cumulative frequencies of occurrence in time of all the winds considered capable of creating a connection with the reefs. Figure 8 presents the stochastic map from a compilation of the source zones connected to the reefs. These zones can be considered as the "recruitment area" of the bay of Marseilles for reef colonization, under the prevailing wind conditions. As our trajectories were computed at each vertical sigma level, we can discriminate "recruitment areas" for connections at the top of the reefs at sigma level 9 located $7 \mathrm{~m}$ above the sea floor (Figure 8(a)), from connections at the bottom of the reefs at sigma level 11 located $2 \mathrm{~m}$ above the sea floor (Figure 8(b)).

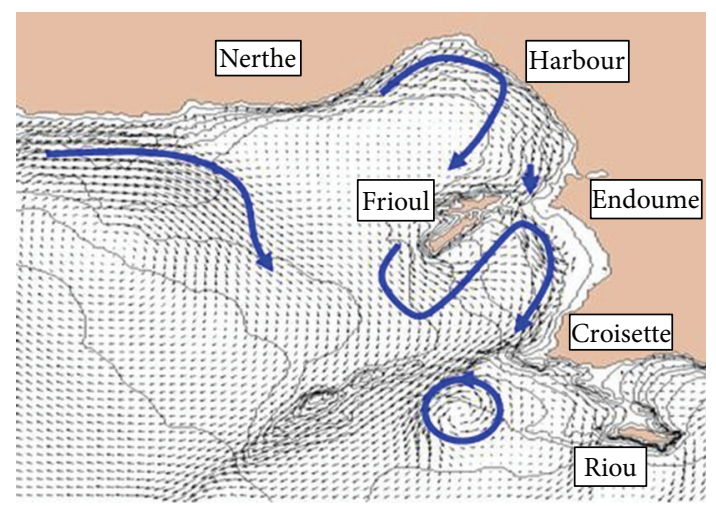

(a)

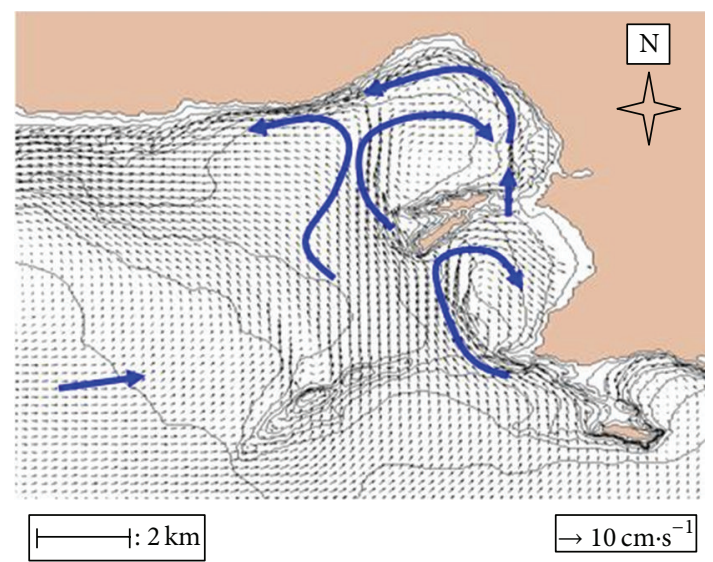

(b)

FIGURE 6: Computed current fields in the bay of Marseilles $(25 \times$ $35 \mathrm{~km}$ ) at $20 \mathrm{~m}$ depth ( $z$ coordinates), under stationary $10 \mathrm{~m} \cdot \mathrm{s}^{-1}$ wind from NW $340^{\circ}$ (a) and SE $120^{\circ}$ (b).

3.4. Influence Zones of Artificial Reefs. Conversely, particle trajectories originating from both the top and the bottom of the reefs, now considered colonized, were computed under the 4 prevailing wind conditions in the bay. This allowed us to draw the stochastic patterns of all the zones impacted by the reef production within the bay. Figure 9 presents, in a comparative way and for each prevailing wind (Figures 9(a), 9(b), 9(c), and 9(d)), the spatial pattern of particle trajectories drifting from the top ( $7 \mathrm{~m}$ above sea floor) and the bottom ( $2 \mathrm{~m}$ above sea floor) of 2 reefs villages chosen as representative of all the reefs, and located at both the NW and SE extremities of the reefs zone (Figure 2).

\section{Discussion}

This study brought new insight on the spatial heterogeneity of the hydrodynamic connections induced by the wind different zones considered throughout the bay of Marseilles. This heterogeneity was widely underestimated by numerous previous environmental studies in the bay. The most meaningful contribution of the present study, compared to our precedent paper [4], was the synthetic analysis of the 


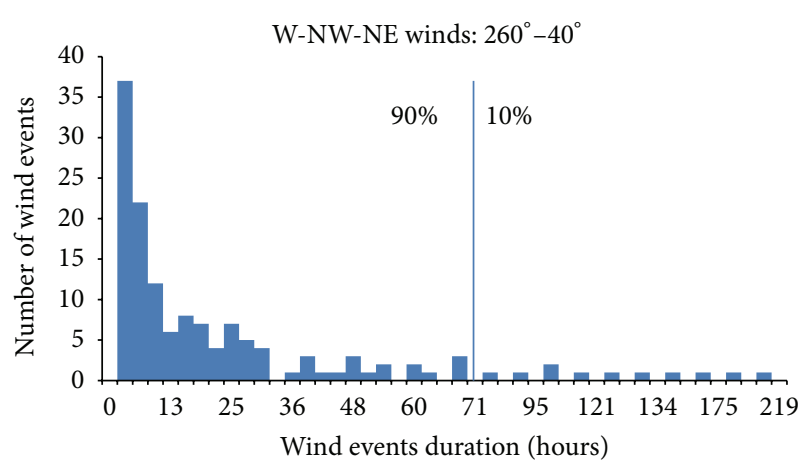

(a)

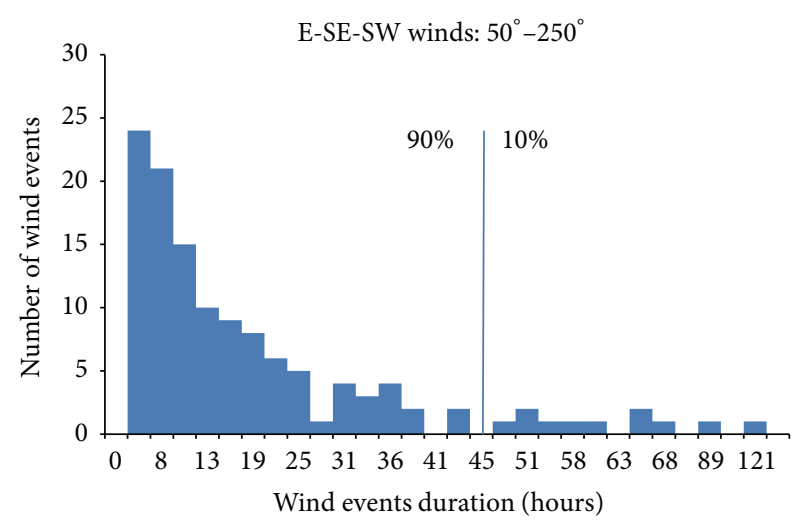

(b)

FIGURE 7: Histograms of relationships between all W-NW-NE (a) and E-SE-SW (b) wind events duration and occurrence frequencies, from statistics computed on 2,800 wind observations at the MétéoFrance station of Pomègues island over the 1976-1998 period.

trajectories computed throughout the bay from all areas identified as source zones of particles for reef colonization within a period of 3 days. The current fields presented in Figure 6 and computed at $20 \mathrm{~m}$ depth, which is not only the depth of artificial structures but also the depth of emission of most of eggs and larvae from source communities, confirmed that distant zones of both the northern and southern shores of the bay were connected by strong and rapid wind-induced fluxes. This confirmation represents a basic knowledge to be considered by decision makers and scientists to improve concepts and interpretations in further projects.

Figure 8(a) emphasized that particles connected to the top of the reefs were essentially released from communities located along the northern part of the bay of Marseille: Nerthe coast, commercial Harbour, and northern Frioul under NW winds. This is not surprising considering the most frequent wind conditions blowing from the NW. Figure 8(b) confirmed the trend of a global southward particle drift for bottom reefs colonization, preferentially from the northern coasts and less frequently from Frioul archipelago under NW $320^{\circ}$ wind. Inversely, reefs colonization by particles drifting from the southern coasts was drastically less frequent than

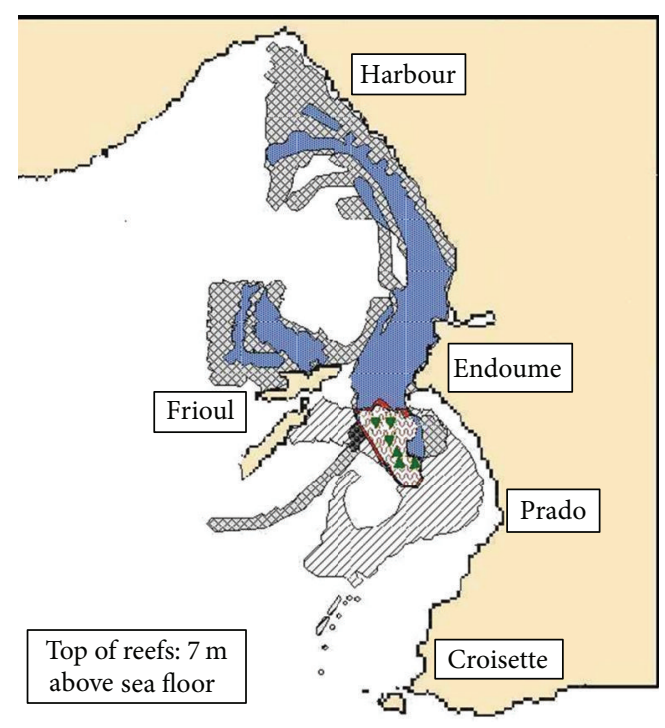

(a)
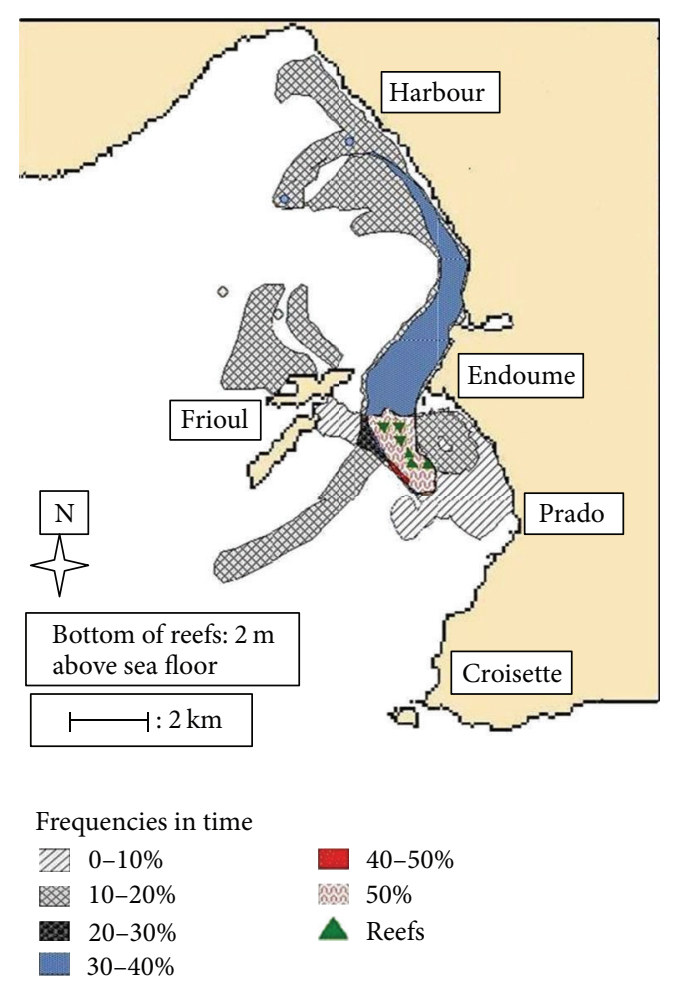

(b)

FIGURE 8: Maps of coastal source zones for artificial reefs in the bay of Marseille, with frequencies of connections with tops of reefs (a) and bottoms of reefs (b), located at $7 \mathrm{~m}$ and $2 \mathrm{~m}$ above the sea floor, respectively.

colonization originating from the northern bay. The colonization at the bottom of the reefs originates from southern coasts, under the only SE $160^{\circ}$ wind condition.

First, the results presented in Figures 8(a) and 8(b) suggested, not surprisingly, that the main recruitment area for reefs colonization by plankton particles, with a frequency 


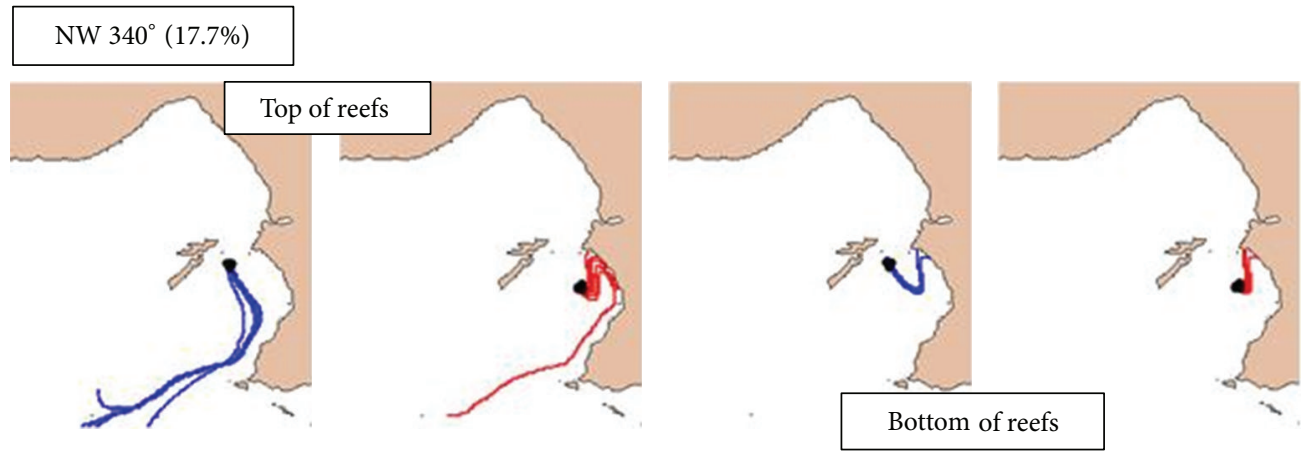

(a)
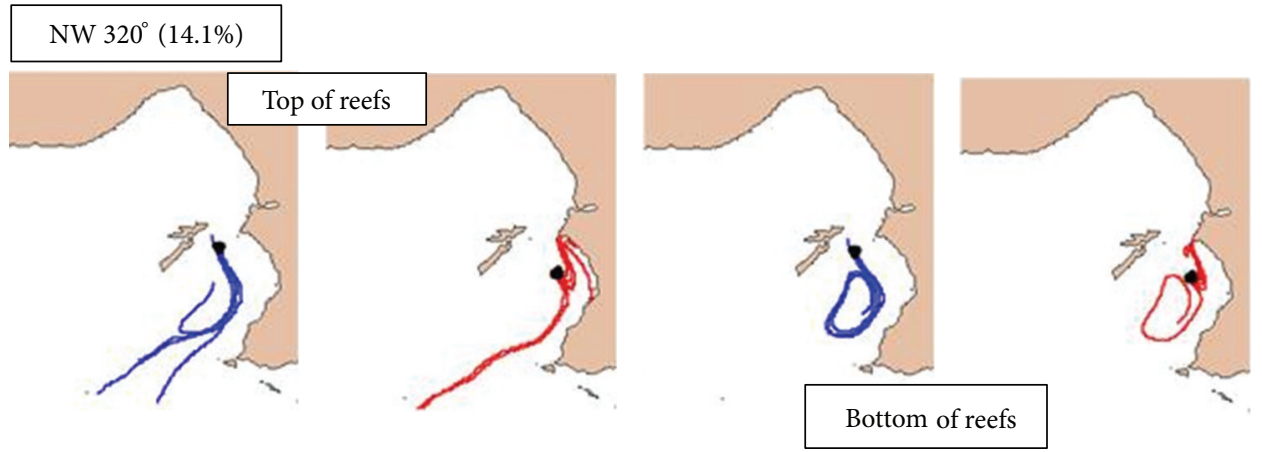

(b)
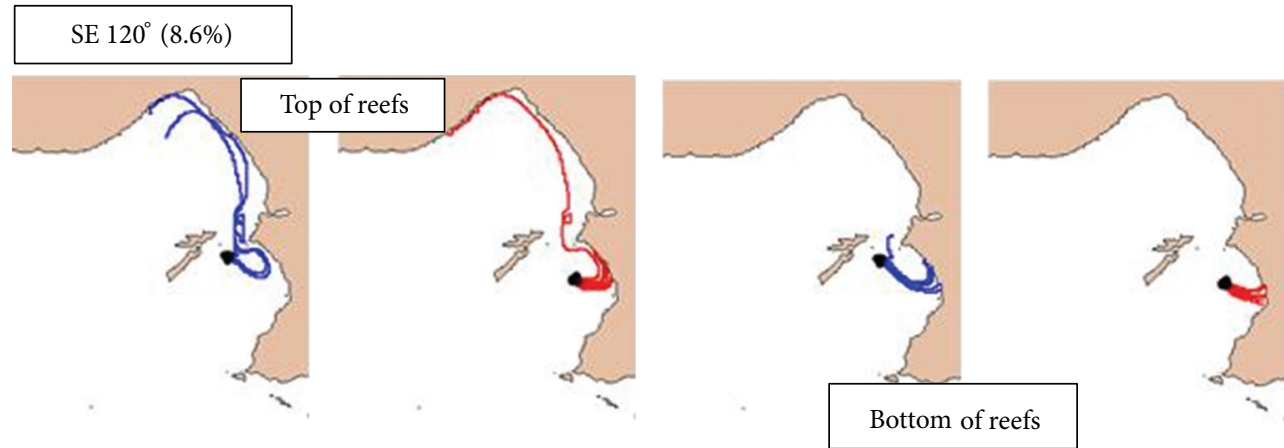

(c)
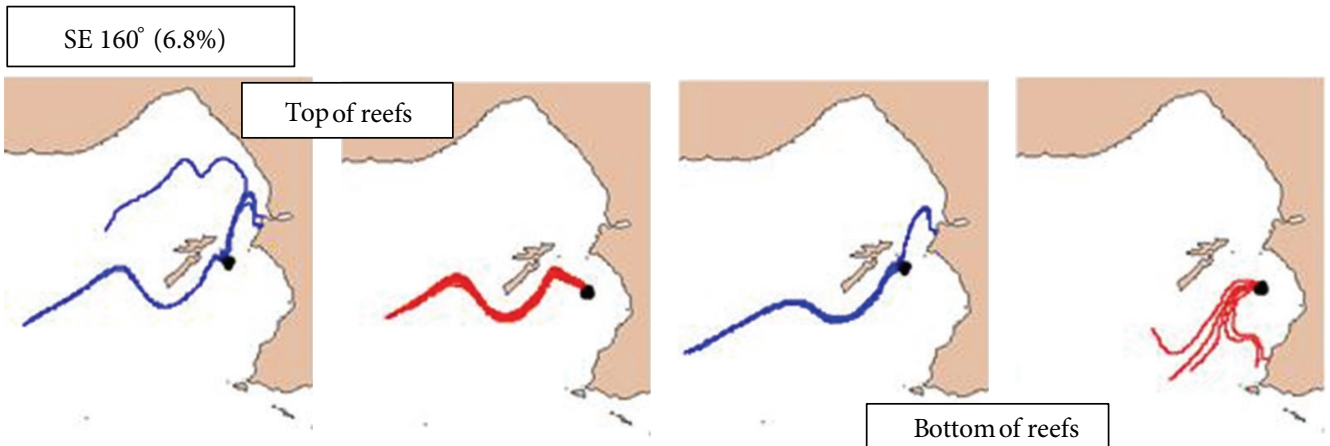

Extreme NW reef

Extreme SE reef

$\longmapsto: 2 \mathrm{~km}$

(d)

FIGURE 9: Comparative patterns of particles trajectories released from both villages located at the extreme NW (blue) and SE (red) of the reefs zone, over a period of 3 days under $10 \mathrm{~m} \cdot \mathrm{s}^{-1}$ wind forcings from NW $340^{\circ}$ (a), NW $320^{\circ}$ (b), SE $120^{\circ}$ (c), and SE $160^{\circ}$ (d). 
reaching almost $50 \%$ of the time, was the area located at the immediate vicinity of the reefs. This elliptic shaped area, slightly stretched along a NW-SE axis, was $2.5 \mathrm{~km}$ long and $1 \mathrm{~km}$ wide. Actually, this area was impacted by the cumulative effects of the 4 prevailing winds accounting for $47.2 \%$ of the time, to which it is pertinent to add the impact of the intermediate SE $140^{\circ}$ wind $(2.2 \%$ of the time), that led to a cumulative frequency of $49.4 \%$ of the time, close to $50 \%$.

Second, Figure 8 emphasized that another highly important recruitment area for the reefs colonization with frequencies reaching $30-40 \%$ of the time was the northeastern shore of the bay between cape of Endoume and the northern end of the commercial Harbour, that represented a maximum distance of $12 \mathrm{~km}$ for particles drifting within a lag of 3 days. The adjacent areas located slightly offshore in the northern bay also presented efficient contributions to the recruitment on the reefs but with weaker frequencies of $10-20 \%$. It is interesting to note the contribution of the northwestern coast off Frioul archipelago, $7 \mathrm{~km}$ away from the reefs, with higher frequencies up to $30-40 \%$ under $\mathrm{NW}$ winds.

Finally, the emission of particles drifting towards the reefs from the southern areas of the bay (western Prado seagrass meadow and the southern Frioul coast) only accounted for $10-20 \%$ of the time. Distances of connections were shorter than those in the northern bay and limited to $6 \mathrm{~km}$ (from the southern Frioul) and only $4 \mathrm{~km}$ (from the Prado meadow). In addition, results confirmed no evident connection over a period of 3 days from the source zones of both northern (Nerthe) and southern (Riou) extremities of the bay. It is interesting to note that these results allowed to forecast a more rapid colonization of artificial reefs located at the northern part of the reefs zone than those located at the southern part (Figure 2).

Figure 9 shows typical trajectories or particles drifting from the reefs. The chosen villages located at both NW and SW extremities of the reefs zone are representative of the other 4 adjacent villages (Figure 2). The orientations of all the trajectories presented a high spatial heterogeneity at short scale, both horizontally and vertically, with opposite directions according to whether particles are released from the NW or NE village, or from the top or the bottom of the reefs. Note that these 2 villages are separated by a short distance of $2 \mathrm{~km}$, and only $5 \mathrm{~m}$ separates the top and the bottom of the reefs. Knowledge of the wind regime in the bay allowed for a stochastic interpretation of Figure 9 and suggested that particles released at the bottom of the reefs ( $2 \mathrm{~m}$ above the sea floor) preferentially drifted southward $40.4 \%$ of the time, to reach the southern shores of the bay under NW and SE $120^{\circ}$ wind combined. Inversely, particles released at the top of reefs still drifted southward $31.8 \%$ of the time under both NW wind forcings, but drifted northward $8.6 \%$ of the time under the only forcing of SE $120^{\circ}$ wind. Moreover, results emphasized the specific impact of the SE $160^{\circ}$ wind, which induced $6.8 \%$ of the time particle motions oriented offshore westward and southwestward, beyond the limits of the inner bay and without any shore landing, both for top and bottom levels. Although this SE $160^{\circ}$ wind-induced situation remains the less frequent of the local wind regime, this situation may represent a risk of loss of a substantial fraction of the biomass produced on the reefs. In addition, results confirmed that particles were drifting relatively far from the reefs over a 3-day period on distances reaching $17 \mathrm{~km}$ towards the northern coasts of the Nerthe, $14 \mathrm{~km}$ westward out of the inner bay, and $11 \mathrm{~km}$ towards the southern coasts off the cape Croisette.

More generally, this study confirmed the spatial heterogeneity of the reefs functioning (i) at the scale of connections with the natural habitats of the bay (a few kilometers), (ii) at the short scale between adjacent villages (1-2 km), and (iii) at the very small scale of the reef structure itself between top and bottom (a few meters). First, results emphasized the general southward polarization of the wind-induced particles drifting throughout the bay. Thus, artificial reefs were preferentially colonized by fluxes drifting from the northern bay $50 \%$ of the time and released particles towards the southern bay $40 \%$ of the time at maximum. Also, villages located in the western or eastern parts of the reef zone frequently showed contrasted particle release, simultaneously oriented in offshore or inshore opposite directions (Figure 9). Finally, the top of the reefs released both southward and northward fluxes of particles $32 \%$ and $8.6 \%$ of the time, respectively, when the bottom of the reefs only released southward $40 \%$ of the time. This spatial differentiation of the reefs functioning at short and small scale will need to be confirmed by further observations collected during the current ecosystem monitoring in the bay.

\section{Acknowledgments}

The authors gratefully acknowledge the Regional Council of Provence-Alpes-Côte d'Azur for having entirely funded this project and Météo-France for providing wind measurements.

\section{References}

[1] S. Perkol-Finkel and Y. Benayahu, "Differential recruitment of benthic communities on neighboring artificial and natural reefs," Journal of Experimental Marine Biology and Ecology, vol. 340, no. 1, pp. 25-39, 2007.

[2] D. A. Siegel, B. P. Kinlan, B. Gaylord, and S. D. Gaines, "Lagrangian descriptions of marine larval dispersion," Marine Ecology Progress Series, vol. 260, pp. 83-96, 2003.

[3] M. A. Pradal, 3D hydrodynamic modelling of the bay of Marseille (France) and relationships between hydrodynamic structures and artificial reefs programme [Ph.D. thesis], Aix-Marseille University, Marseille, France, 2006.

[4] M. A. Pradal and B. Millet, "Spatial heterogeneity of wind forcing: application to artificial reef functioning influenced by the circulation in the Bay of Marseilles, France," Comptes Rendus-Biologies, vol. 329, no. 7, pp. 541-550, 2006.

[5] A. F. Blumberg and G. L. Mellor, "A description of a three-dimensional coastal ocean circulation model," in ThreeDimensional Coastal Ocean Models, N. Heaps, Ed., American Geophysical Union, Washington, DC, USA, 1987.

[6] Hydrographic and Oceanographic Department of the french Navy (SHOM), Map 6767-1/50000, 1981. 
[7] I. L. Pairaud, J. Gatti, N. Bensoussan, R. Verney, and P. Garreau, "Hydrology and circulation in a coastal area off Marseille: validation of a nested 3D model with observations," Journal of Marine Systems, vol. 88, no. 1, pp. 20-33, 2011. 

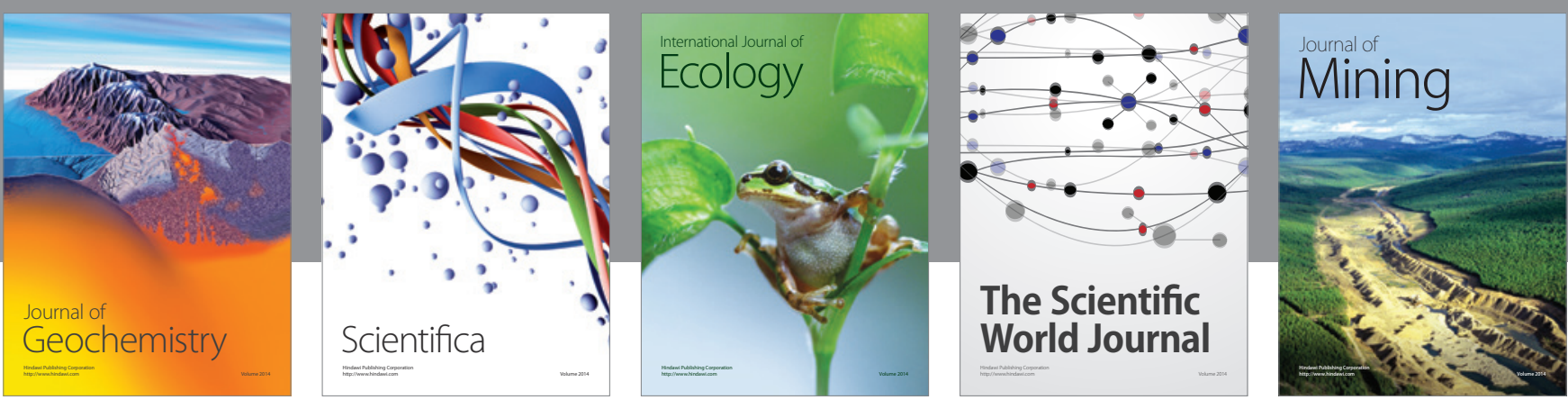

The Scientific World Journal
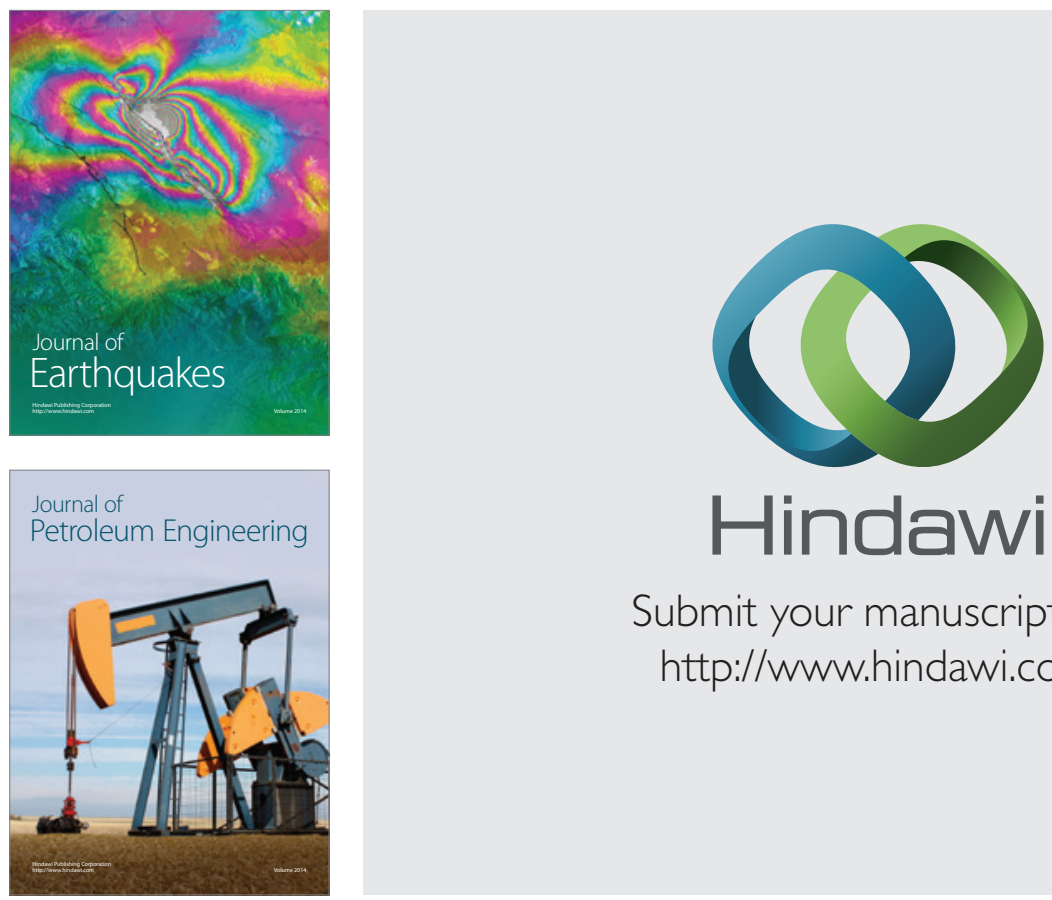

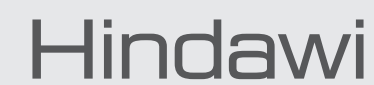

Submit your manuscripts at

http://www.hindawi.com
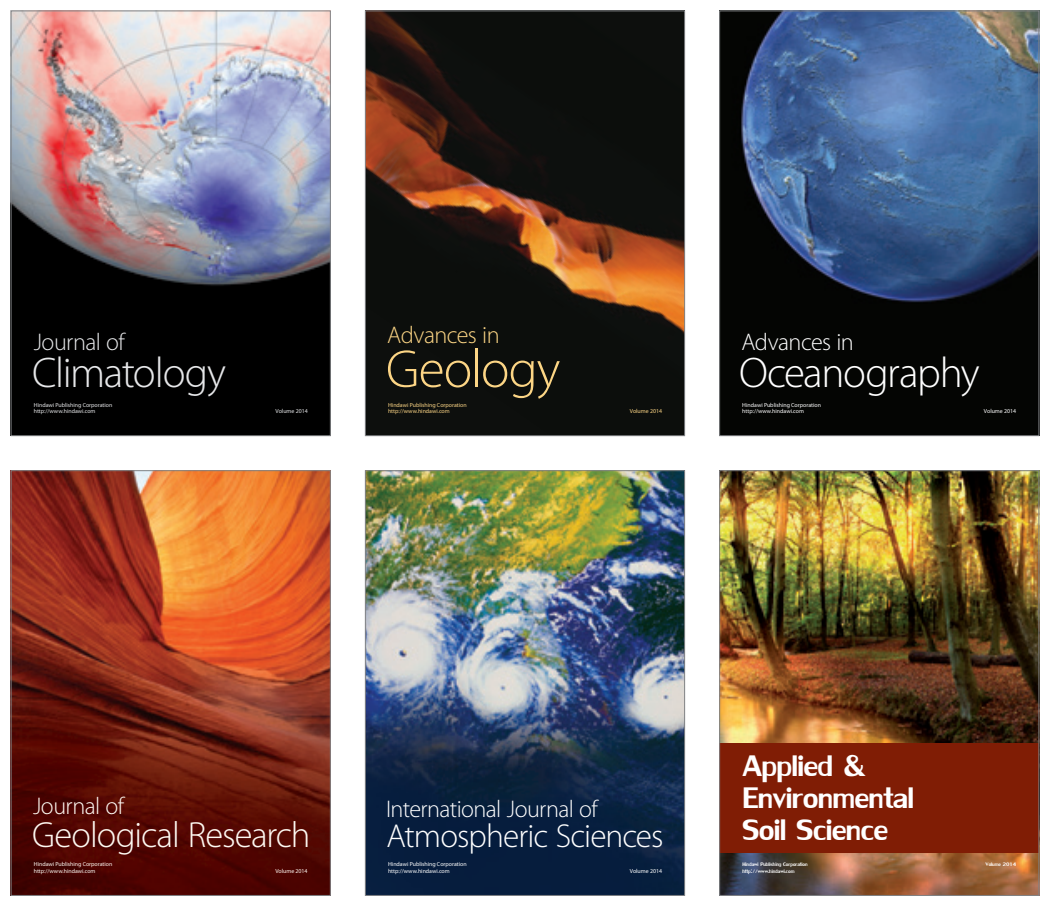
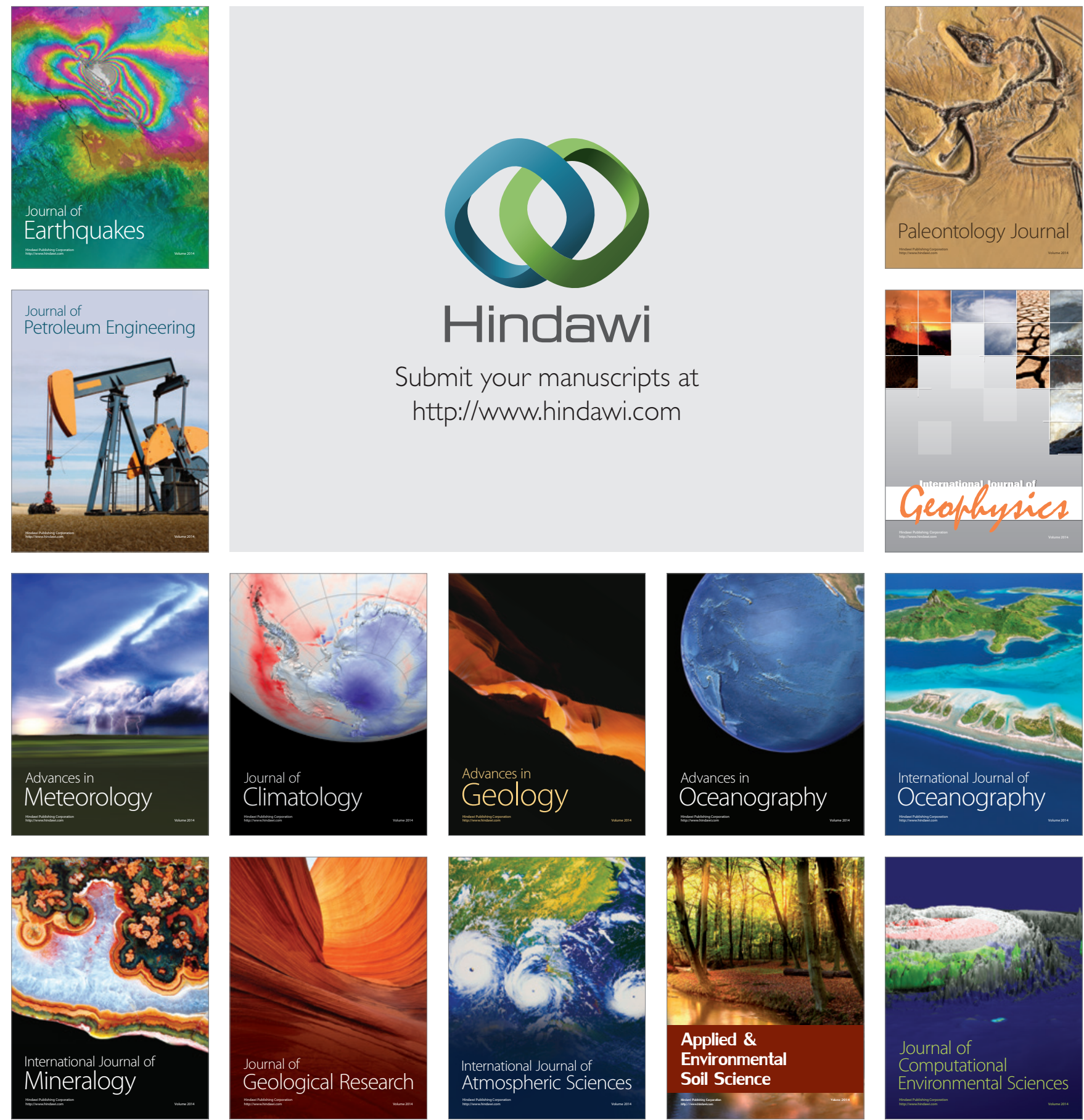